\title{
Prediction of aeroacoustic performance of counter-rotating wind turbine by changing the rotational speed of front rotor
}

\author{
Elham Abohamzeh ${ }^{1} \cdot$ M. Jamil ${ }^{1} \cdot$ Ali Cemal Benim $^{2}$
}

Received: 7 September 2019 / Accepted: 7 December 2019 / Published online: 14 December 2019

(c) Springer Nature Switzerland AG 2019

\begin{abstract}
This study aims to investigate the aerodynamic and aeroacoustic performance of a counter-rotating wind turbine (CRWT) to define the effect of rotational wind speed of the front rotor on the sound pressure level of CRWT, using CFD simulation. For this purpose, NREL Phase VI wind turbine was considered as the single rotor, and validation of aerodynamic and aeroacoustic simulation has been carried out for the solver. Then, 3D simulation has been applied on single rotor and counter-rotating wind turbines to scrutinize the acoustic level of CRWT by changing the rotational speed of the front rotor. The unsteady flow simulation was carried out with the realizable $k-\varepsilon$ Reynolds-averaged Navier-Stokes turbulence model, and the calculated flow field data were utilized using Ffowcs Williams-Hawkings model for predicting the acoustic level at receiver location, defined based on the IEC61400-11 standard. The results show that increasing the rotational wind speed of the upstream rotor leads to augmenting the noise emitted from CRWT. On the other hand, for tip speed ratios (TSR) ranging from 6 to 12, with increasing the front rotor RPM, the power coefficient of CRWT enhances, while for the TSR more than 12, an inverse behavior has been observed and power coefficient declines along with increasing front rotor's speed of revolution.
\end{abstract}

Keywords Counter-rotating wind turbine (CRWT) - CFD modeling · Aerodynamics · Aeroacoustics · Ffows WilliamsHawkings method $\cdot$ Noise analysis

\section{List of symbols}

A Blade swept area $\left(\mathrm{m}^{2}\right)$

$c_{0} \quad$ Speed of sound $(\mathrm{m} / \mathrm{s})$

CRWT Counter-rotating wind turbine

$f \quad$ Function defining location of control surface

FW-H Ffowcs Williams-Hawkings model

$\mathrm{H} \quad$ Heaviside function

L Blade span (m)

$I_{i} \quad$ Local force vector components exerted by the surface on fluid $(\mathrm{N})$

$\mathrm{n} \quad$ Number of the blades

$n_{i} \quad$ Normal unit vector

$\mathrm{p} \quad$ Surface pressure (static) (Pa)

$P_{\text {in }} \quad$ Power in wind flow

$P_{\text {out }} \quad$ Mechanical power extracted from the wind $p_{i j} \quad$ Compressive stress tensor ( $\left.\mathrm{Pa}\right)$

RANS Reynolds-averaged Navier-Stokes

$r_{i} \quad$ Component of unit vector in radiation direction

$r_{j} \quad$ Radiation vector between observer and source at emission time $(\mathrm{m})$

S Surface area $\left(\mathrm{m}^{2}\right)$

$\mathrm{t} \quad$ Observer time (s)

$T_{i j} \quad$ Lighthill stress tensor ( $\left.\mathrm{Pa}\right)$

TSR Tip speed ratio

$u_{i} \quad$ Velocity $(\mathrm{m} / \mathrm{s})$

$v_{0} \quad$ Free stream velocity $(\mathrm{m} / \mathrm{s})$

$v_{i} \quad$ Control surface velocity $(\mathrm{m} / \mathrm{s})$

$x_{i} \quad$ Observer location $(\mathrm{m})$

$y_{i} \quad$ Source location $(m)$

Elham Abohamzeh, elhamaboohamzeh@gmail.com | ${ }^{1}$ Department of Energy, Materials and Energy Research Center (MERC), Karaj, Iran. ${ }^{2}$ Department of Mechanical and Process Engineering, Center of Flow Simulation (CFS), Duesseldorf University of Applied Sciences, Duesseldorf, Germany. 


\section{Greek symbols \\ $\rho \quad$ Air density in \\ $\omega \quad$ Angular velocity \\ $\mu \quad$ Dynamic viscosity}

\section{Introduction}

In recent decades wind energy, which is a renewable energy source, has been considered as an appropriate alternative for fossil fuels in the energy market worldwide. The development of the wind energy industry helps to decrease the dependency on fossil fuel. As a result, many researchers have studied different aspects of wind turbines numerically and experimentally [1-3]. Since wind energy sources, as well as suitable sites (both onshore and offshore locations) for installing wind turbines, are limited, wind turbines with higher efficiency are needed. Consequently, quite a bit of research has been carried out to find solutions to gain more energy from available wind sources. HAWT systems that are much more widely used have a rotor as well as an electrical generator installed at the top of a tower. The maximum efficiency of such a wind turbine is $59 \%$ based on the Betz limit, while according to Newman [4], by adding an additional rotor with the same swept area, this limit will be increased to $64 \%$. Counter-rotating wind turbines have been introduced to increase the efficiency of wind turbines, reducing the wake losses. This is the reason for many recent studies on CRWTs, which are proposed as an effective solution to absorb more energy from wind. The main concept behind CRWTs is harnessing the residual energy in the wake of the first rotor by the additional rotor, which is installed in the downstream of the front rotor. CRWTs with two rotors having the same or different diameters have been considered as an effective solution to get more energy form the same wind source and have become a favorite topic for analysis.

NREL Phase VI wind turbine, which is selected as the base model of this study, was tested experimentally by NREL in NASA wind tunnel. NREL published the test outputs as well as wind turbine design information [5]. This information has been utilized by many researchers for verifying their codes. The performance of this turbine has been studied numerically in quite a bit of research, aiming to have an accurate prediction of nearfield flow. Park et al. [6] carried out a CFD simulation on different sizes of NREL Phase VI wind turbine to investigate the performance of various sizes and study scale effect, using FLUENT software. They have found out that the results obtained by the realizable $k-\varepsilon$ turbulence model have the best agreement with experimental as well as blind test data. In this research, they presented a new method for the correction of wind turbine scale effects. To validate their correction method, they also tested $12 \%$ NREL Phase VI scale model in the wind tunnel, and the results showed a great correlation with the data obtained by CFD simulation. Jang and Joung [7] investigated the aerodynamic performance of NREL Phase VI wind turbine through performing 3D simulation. In this research, validation of torque produced by NREL Phase VI wind turbine was performed considering the results from [5-7]. Different studies have been carried out to predict the effect of having an auxiliary rotor on the performance of wind turbines. A preliminary version of CRWT with $6 \mathrm{Kw}$ capacity was fabricated and tested in 2003 in the USA, and the results show up to $40 \%$ more power comparing to the SRWT case. This work revealed that CRWT systems have better performance at low rotor velocities (16-20 RPM) that shows these CR wind turbines can be used in utility-scale wind turbines rotating at these rotational speeds [8]. Jung et al. [9] investigated a $30 \mathrm{~kW}$ CRWT performance, which had a generator with a differential planetary system. The experimental data of the scaled model rotor was used for predicting the wake behavior of the secondary rotor located upwind of the first rotor. The Blade Element Momentum theory, combined with Experimental Wake Model, was used in order to define the optimized rotor's sizes and their axial distance. The performance of CRWT was compared with SRWT, and $21 \%$ power increase was observed in the rated power. Lee et al. [10] studied the performance of CRWT and SRWT, applying the free wake vortex lattice method and compared the obtained results. To have a fair comparison, he compared the performance of the CRWT with that of an SRWT model with the same solidity as well as an SRWT with half solidity. The outputs showed that maximum $C_{p}$ of CRWT is $30 \%$ more than that of SRWT with half solidity, but $5 \%$ less than SRWT with the same solidity. Habash et al. [11] carried out wind tunnel tests on a scaled model of CRWT under different operational conditions and different Reynolds numbers to investigate the effect of counterrotating wind turbine configuration on its performance. The results show that in the same condition, CRWT could produce $20-40 \%$ more power in comparison to SRWT. The results also show that CRWT may produce up to $60 \%$ more power compared to SRWT. Moreover, the main problem of wind turbines, which is the performance in low-wind, by using CRWT would be solved since it can decrease the cut-in wind speed at the same time keeping the performance. Ozbay et al. [12] studied experimentally the wake specification as well as performance of dual-rotor wind turbines in two different positioning, counter-rotating (CR) and co-rotating (CO), with a fixed distance of 0.25 diameter between front and rear rotors, and compared the performance of these models with single-rotor wind turbine (SRWT). The specification of flow around the wind turbines was quantified using a particle image velocimetry 
(PIV) system. They found out that under the same circumstances, COWT produces $48 \%$ and CRWT $60 \%$ more power than conventional SRWT, since in CRWT configuration, the swirling velocity in the wake flow of the front rotor has the same direction as the rear rotor, and this velocity apply an additional torque on the rear rotor. This means that the downwind rotor will absorb more kinetic energy. This is revealed in free-run PIV measurement results since the velocity deficits are higher in the wake flow of the CRWT. Investigating static and dynamic loads acting on SRWT and DRWT shows that forces in DRWT are much higher than that of acting on SRWT, which increases the production and maintenance cost of these models. Wang et al. [13] evaluated experimentally the performance of a dual-rotor wind turbine using a PIV system, in two different conditions, isolated condition and wind farm scenario. They observed that in DRWTs, aerodynamic losses in the root region of the blade decrease, which leads to more power production in an isolated condition, and the efficiency increases in the wind farm scenario resulting from augmenting the turbulent mixing in the wake area of DRWT. Koehuan et al. [14] studied the performance of CRWT through CFD simulation considering non-dimensional parameters, which are diameter ratios, the axial distance between two rotors and power coefficient, and compared the performance in different configurations for a variety of tip speed ratios (TSR). They found out that when the diameter ratio $\mathrm{D} 1 / \mathrm{D} 2=1$ at relative $\mathrm{TSR}=9.6$, the max of power coefficient equal to 0.5219 , which is $16.49 \%$ greater than that of SRWT, can be achieved. The maximum total $C_{p}$ is observed in the ratio $D 1 / D 2=1$. Following the increase of axial distance, $C_{p}$ of the front rotor gets larger and becomes closer to the power coefficient of the single rotor, while this has a negative impact on rear rotor performance. Hwang et al. [15] applied BEM (blade element momentum) theory in order to optimize a Counter Rotating wind turbine using this assumption that the rear blade is located in the fully developed region of the front rotor. Considering rotational speeds, radius ratios, and pitch angles of two rotors as design parameters and applying torque balance, power and trust coefficients were evaluated. By applying BEM theory on the front rotor, power and trust coefficients were defined. The data which was defined at this step was considered as input data for the rear rotor. It must be mentioned that the study is carried out considering a constant distance of $0.33 \mathrm{D}$ between the front and rear rotor, and since they couldn't confirm that the flow in this distance is fully developed, the flow model for BEM theory was corrected by Vortex Lattice Method. Based on the optimization results, which were obtained using a genetic algorithm, they found out that for higher efficiency, a smaller size should be considered for the front blade rather than the rear blade. Furthermore, in spite of the smaller rotor, the front rotor has a higher efficiency in the optimized design.

The prerequisite of the study on solutions for reducing aerodynamic noise of wind turbines, which is a limiting factor for developing wind energy, especially the small ones which are going to install in residential areas, is an exact prediction of aerodynamic noise radiated from wind turbines. Advanced computing facilities have provided researchers with the opportunity of applying computational aeroacoustic analysis utilizing the flow field data, which is gained by CFD solvers. Tadamasa and Zangeneh [16] carried out a study on NREL phase $\mathrm{VI}$ wind turbine to calculate emitted noise according to $\mathrm{FW}-\mathrm{H}$ equations. They defined the flow parameters required for acoustic prediction using Reynolds averaged Navier-Stokes (RANS). Using FW-H codes, they studied the contributions of different types of noise. Mo et al. [17] studied the acoustic specification of NREL Phase VI wind turbine using Fluent software. They calculated the flow field data around the wind turbine by the LES turbulence model and predicted the noise generated by the Ffows Williams-Hawkings method. They observed that tip vortices produced from a rotating wind turbine create aerodynamic noise. Obtained results were in a satisfactory agreement with previous studies. Maizi et al. [18] carried out a numerical simulation on $12 \%$ scaled model of NREL Phase VI wind turbine, aiming to reduce the noise generated by the wind turbine without considerable influence on the power performance. They considered three different blade shapes; standard blade, reference tip blade, and sharp tip blade, and performed aeroacoustic analysis. They found out that the shark tip blade is the most efficient configuration with $7 \%$ reduction in noise and only $3 \%$ reduction in power compared with the standard blade. Giridhar et al. [19] predicted noise radiated from NREL Phase VI wind turbine by performing 3D computational simulation under different wind velocities. SST $k-\omega$ RANS turbulence has been used in a steady analysis to calculate flow field data. Flow field data were utilized to estimate acoustic power distribution on the blade surface through the Curle Broadband Noise Source model. Also, the sound level at the location of the receiver was defined by applying Improved Delayed Detached Eddy Simulation and Ffowcs Williams-Hawkings model. Zhu et al. [20] carried out a comprehensive review, including a variety of noise generation and propagation models developed for wind turbines in the technical university of Denmark. These various models were presented and analyzed with attention to numerical modeling. Also, the state-of-theart models for noise prediction under complex inflow conditions have been presented. These models have also been explained according to their computational 
cost requirements as well as applications. Ghasemian et al. [21] applied Improved Delayed Detached Eddy turbulence model for simulating the flow around NREL phase VI wind turbine and Ffowcs William and Hawkings (FW-H) acoustic analogy to estimate the emitted noise at different wind speeds, as well as different distances in the range from 20 to $140 \mathrm{~m}$. The influence of changing the distance of receiver and wind velocity on Overall Sound Pressure Level (OASPL) has been studied by comparison of the outputs.

Despite many studies that investigated different aspects of CRWTs, very little attention has been paid to noise generated by these turbines. The emitted noise is one of the most critical issues associated with wind turbine technology since these wind generators are installed in or near residential areas, and when acoustic levels are higher than what is allowed in regulations and
A variety of parameters such as the purpose of the study, the physical condition of the problem, the desired accuracy, the available computer performance, the model which was used by previous research for the same problem must be considered before selecting a turbulence model.

In the present study, the realizable $k-\varepsilon$ turbulence model is used, which was also mentioned by [6] to provide results exhibiting a quite good agreement with the experimental data in a similar problem.

\subsubsection{Transport equations for the realizable $k-\varepsilon$ model}

The realizable $\mathrm{k}-\varepsilon$ model, which was applied in this study, has been suggested by Shih et al. [22]. In this model, transport equations for turbulent kinetic energy $k$ and dissipation rate $\varepsilon$ are as follows:

$$
\begin{aligned}
& \frac{\partial}{\partial t}(\rho k)+\frac{\partial}{\partial x_{i}}\left(\rho k u_{j}\right)=\frac{\partial}{\partial x_{i}}\left[\left(\mu+\frac{\mu_{t}}{\sigma_{k}}\right) \frac{\partial k}{\partial x_{j}}\right]+G_{k}+G_{b}-\rho \varepsilon-Y_{M}+S_{k} \\
& \frac{\partial}{\partial t}(\rho \varepsilon)+\frac{\partial}{\partial x_{j}}\left(\rho \varepsilon u_{j}\right)=\frac{\partial}{\partial x_{j}}\left[\left(\mu+\frac{\mu_{t}}{\sigma_{\varepsilon}}\right) \frac{\partial \varepsilon}{\partial x_{j}}\right]+\rho C_{1} S_{\varepsilon}-\rho C_{2} \frac{\varepsilon^{2}}{K+\sqrt{v \varepsilon}}+C_{1 \varepsilon} \frac{\varepsilon}{k} C_{3 \varepsilon} G_{b}+S_{\varepsilon}
\end{aligned}
$$

standards, it could annoy people. Predicting noise radiated from CRWTs can lead to finding solutions to reduce the emitted noise and help to develop these interesting novel wind turbines. Therefore, this article study not only the power performance of these turbines but also the generated aerodynamic noise by these turbines. The influence of rotational speeds changes of the front rotor on the total noise generated by a three-bladed CRWT has been investigated in the current study.

\section{Governing equations}

\subsection{Turbulence model}

The ensemble-averaged continuity and momentum equations for turbulent flow are represented as follows:

$\frac{\partial \rho}{\partial t}+\frac{\partial\left(\bar{u}_{i}\right)}{\partial x_{i}}=0$ where $G_{k}$ is the production of turbulence kinetic energy due to average velocity gradients, $G_{b}$ represents turbulence kinetic energy due to buoyancy, $Y_{M}$ is the contribution due to compressibility, $S_{k}$ and $S_{\varepsilon}$ are source terms which are defined by the user, $C_{1}, \eta$ and $S$ are constants which can be determined by the following equations:

$C_{1}=\max \left[0.43 \cdot \frac{\eta}{\eta+5}\right]$

$\eta=S \frac{k}{\varepsilon} S=2 \sqrt{S_{i j} S_{i j}}$

The eddy viscosity is calculated as follows:

$\mu_{t}=\frac{1}{\varepsilon} K^{2} C_{\mu} \rho_{n f}$

For the Realizable $\mathrm{k}-\varepsilon$ turbulence model, the constant terms take the values.

$C_{1 \varepsilon}=1.44, C_{2}=1.9, \sigma_{k}=1.0, \sigma_{\varepsilon}=1.2$

$\rho \frac{\partial \bar{u}_{i}}{\partial t}+\frac{\partial\left(\rho \bar{u}_{i} \bar{u}_{j}\right)}{\partial x_{i}}=-\frac{\partial P}{\partial x_{j}}+\frac{\partial}{\partial x_{j}}\left[\mu\left(\frac{\partial \bar{u}_{i}}{\partial x_{j}}+\frac{\partial \bar{u}_{j}}{\partial x_{i}}-\frac{2}{3} \delta_{i j} \frac{\partial \bar{u}_{j}}{\partial x_{i}}\right)\right]+\frac{\partial}{\partial x_{j}}\left(-\rho \bar{u}_{i}^{\prime} \bar{u}_{j}^{\prime}\right)$ 


\subsection{Acoustic analogy}

The first equation of aerodynamic noise based on the analogy of sound radiated by fluctuating monopole, dipole, or quadrupole aeroacoustic sources was proposed by Lighthill [23]. Then it was developed by Curle [24] by including the influence of static boundaries. Ffocs Williams-Hawkings [25] have presented a method to predict the noise emitted from objects in motion by considering the influence of the moving solid body in Lighthill's acoustic analogy. The influence of flow was studied carefully by Ffowcs Williams et al. [26].

FW-H (Ffowcs Williams-Hawkings) analogy has been applied in this research to predict the noise emitted from the turbine in both SRWT and CRWT cases. Time histories of generated sound pressure at a specified receiver location can be calculated in ANSYS-FLUENT. Time-accurate parameters such as velocity, pressure, and density on the control surface, which are required for acoustic analysis, were computed using URANS equations. Various acoustic sources, as well as different receivers, can be selected and analyzed using the FW-H acoustics model in FLUENT [27].

\subsubsection{Ffowcs Williams-Hawkings equations}

The Ffowcs Williams-Hawkings (FW-H) equation, an inhomogeneous wave equation obtained by rearranging continuity as well as Navier-Stokes ( $\mathrm{N}-\mathrm{S}$ ) formulations, is used to define the acoustic level at a defined receiver which is located in a certain point placed downstream of the acoustic source. The nearfield flow data required for calculating the acoustic pressure are obtained from CFD analysis. The $\mathrm{FW}-\mathrm{H}$ formulation is written as follows: $u_{i}$ and $v_{i}$ are fluid and surface components in the $x_{i}$ direction, and $u_{n}$ and $v_{n}$ are the fluid velocity and control surface velocity in the direction normal to control surface. $H(f)$ Heaviside function and $\delta(f)$ is the Dirac delta function. In the above equation, the value in $\mathrm{f}$ is defined by subscript 0 . The primed value denotes the difference between the value in the undisturbed medium and in the real state. $p^{\prime}$ is defined as: $p^{\prime}=c_{0}^{2}\left(\rho-\rho_{0}\right)$.

$p_{i j}$ is compressive stress tensor which can be written as:

$P_{i j}=p \delta_{i j}-\mu\left[\frac{\partial u_{i}}{\partial x_{j}}+\frac{\partial u_{j}}{\partial x_{i}}-\frac{2}{3} \frac{\partial u_{k}}{\partial x_{k}} \delta_{i j}\right]$

In order to facilitate the use of generalized function theory and Green function to achieve the solution, a mathematical surface that introduces a discontinuity in the unbounded fluid domain was represented. The motion and shape of this control surface which represents the source surface (blade and shaft), is determined by $f(\vec{x} . t)$. with $f<0$ for the interior region and $f>0$ for the exterior region.

Using the free-space Green function at the location of the receiver of a far-field, the solution of Eq. (12) is obtained:

$G(\vec{x} . t ; \vec{y} . \tau)=\left\{\begin{array}{l}0 . \tau>t \\ \frac{\delta(g)}{4 \pi r} \cdot \tau \leq t\end{array}\right.$

where

$g=\tau-t+r / c_{0}$

$r$ is the distance of the observer from the noise source, $\tau$ is the time when noise is emitted from the source, and $t$ is the time when the observer receives noise [28].

$\frac{1}{c_{0}^{2}} \frac{\partial^{2} p^{\prime}}{\partial t^{2}}-\nabla^{2} p^{\prime}=\frac{\partial^{2}}{\partial x_{i} \partial x_{j}}\left\{T_{i j} H(f)\right\}-\frac{\partial}{\partial x_{i}}\left\{\left[P_{i j} n_{j}+\rho u_{i}\left(u_{n}-v_{n}\right)\right] \delta(f)\right\}+\frac{\partial}{\partial t}\left\{\left[\rho_{0} v_{n}+\rho\left(u_{n}-v_{n}\right)\right] \delta(f)\right\}$

Where $c_{0}$ is the speed of sound in far-field, and $T_{i j}$ is the Lighthill stress tensor:

$T_{i j}=\rho u_{i} u_{j}+p_{i j}-c_{0}^{2}\left(\rho-\rho_{0}\right) \delta_{i j}$
The total acoustic pressure of the retarded-time formulation of FW-H equation can be defined as follows:

$P^{\prime}(\vec{x} . t)=P_{T}^{\prime}(\vec{x} . t)+P_{L}^{\prime}(\vec{x} . t)$

Where.

$$
\begin{aligned}
& 4 \pi P_{T}^{\prime}(\vec{x} . t)=\int_{f=0}\left[\frac{\rho_{0}\left(\dot{U}_{n}+U_{\dot{n}}\right)}{r\left(1-M_{r}\right)^{2}}\right] d S+\int_{f=0}\left[\frac{\rho_{0} U_{n}\left\{r \dot{M}_{r}+a_{0}\left(M_{r}-M^{2}\right)\right\}}{r^{2}\left(1-M_{r}\right)^{3}}\right] d s \\
& \pi P_{L}^{\prime}(\vec{x} . t)=\frac{1}{a_{0}} \int_{f=0}\left[\frac{L_{r}}{r\left(1-M_{r}\right)^{2}}\right] d s+\int_{f=0}\left[\frac{L_{r}-L_{M}}{r^{2}\left(1-M_{r}\right)^{2}}\right] d s+\frac{1}{a_{0}} \int_{f=0}\left[\frac{L_{r}\left\{r \dot{M}_{r}+a_{0}\left(M_{r}-M^{2}\right)\right\}}{r^{2}\left(1-M_{r}\right)^{3}}\right] d s
\end{aligned}
$$


Table 1 Specification of CRWT

\begin{tabular}{lll}
\hline Specifications & Front rotor & Rear rotor \\
\hline Number of blades & 3 & 3 \\
Rotor diameter & $5.029 \mathrm{~m}$ & $10.058 \mathrm{~m}$ \\
Distance between rotors & $2.015 \mathrm{~m}$ & \\
Rotor position & Upwind & Downwind \\
Rotation direction & Clockwise & Counterclockwise
\end{tabular}

Where:

$U_{i}=\left(1-\frac{\rho}{\rho_{0}}\right) v_{i}+\frac{\rho u_{i}}{\rho_{0}}$

$L_{i}=P_{i j} n_{j}+\rho u_{i}\left(u_{n}-v_{n}\right)$

\section{Physical model}

\subsection{Single rotor wind turbine and counter-rotating wind turbine geometry}

The wind turbine selected for this study is NREL Phase VI since there are enough data about its aerodynamic and acoustic performance. NREL Phase VI with airfoil S809 is a wind turbine operating with a stall-regulated method and has $10.058 \mathrm{~m}$ diameter and $19.8 \mathrm{~kW}$ rated power. It rotates with a constant $72 \mathrm{rpm}$ rotational speed and has a hub height of $12 \mathrm{~m}$. After validation of CFD analysis through comparison with results from previous studies, the numerical study has been performed for the three-blade configuration of NREL Phase $\mathrm{VI}$, since this configuration has been proved to be the most efficient design.

The information on CRWT based on NREL Phase VI wind turbine is specified in Table 1 . The front rotor, located upstream, is $50 \%$ scaled. The distance ratio is $0.5 \mathrm{~d}$, $\mathrm{d}$ is the front rotor's diameter.

\subsection{Boundary conditions and meshing}

The domain used for the computational study is a cylinder consists of two rotating regions which present front and rear rotors and a stationary surrounding region. The domain diameter is 10 times, and the domain height is 16 times larger than the diameter of the rear rotor.

As boundary conditions, inlet velocity is defined in the inlet section and pressure outlet on the outlet section

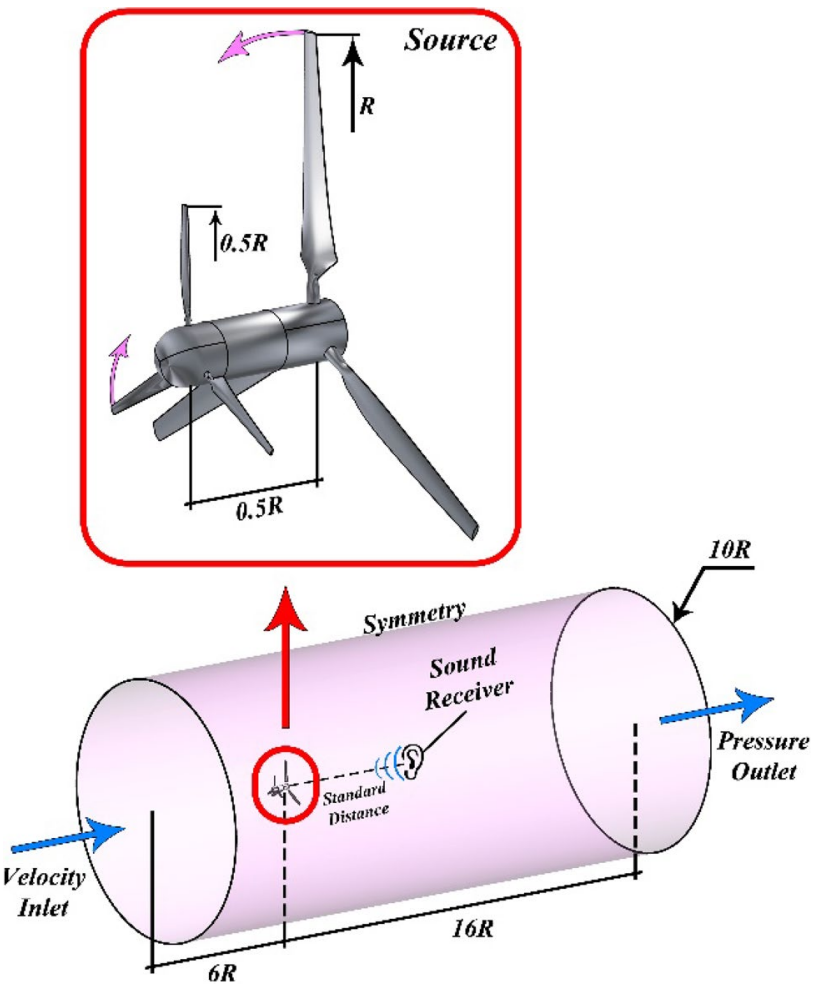

Fig. 1 Configuration of counter-rotating wind turbine

where the flow leaves. Blade and hub surfaces are set as no-slip wall boundary condition, and the sides are symmetry boundaries. The simulation is carried out on $1 / 3$ of the domain considering $120^{\circ}$ periodic boundary condition to decrease computational cost and time. The geometry of the counter-rotating wind turbine, as well as applied boundary conditions, are illustrated in Fig. 1.

The created mesh, which was used for domain discretization, is an unstructured mesh containing 7,829,504 tetrahedral cells, as shown in Fig. 2. For the purpose of accurate simulation of flow, very fine mesh size was applied near the leading and trailing edges of the front and rear blades. Aiming to obtain the appropriate $y+$ value for the realizable $\mathrm{k}-\varepsilon$ turbulence model, unstructured meshes with inflation layers on walls were utilized by employing first layer thickness as also recommended by [1]. The maximum amounts of $y+$ on surfaces of front and rear blades have been reported in Table 2 .

The quality of mesh was checked considering maximum skewness and maximum orthogonal quality, which are $0.89,608$ and $0.95,168$, respectively. 


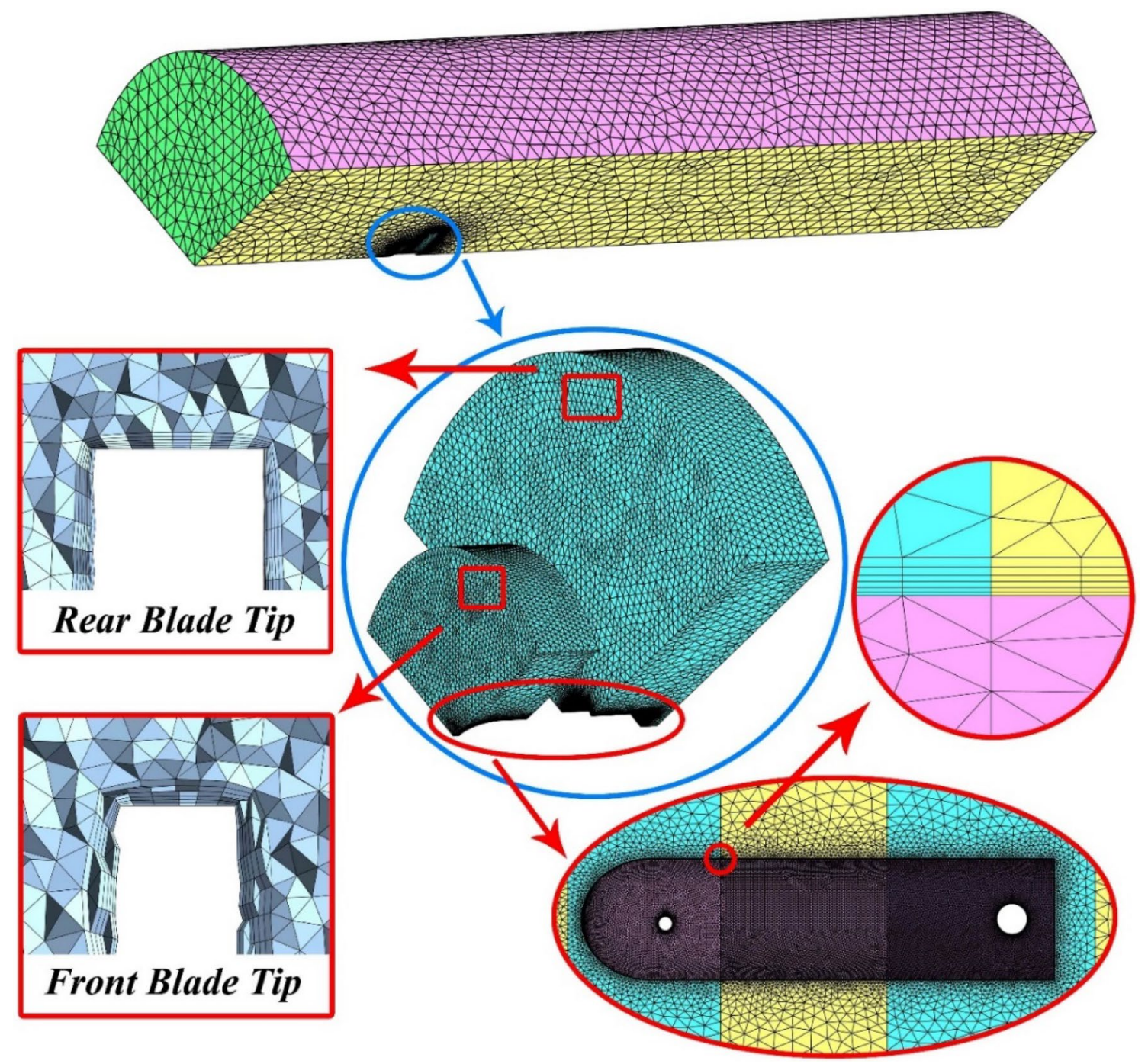

Fig. 2 Computational meshes of domain

Table $2 \mathrm{y}^{+}$value for front and rear rotors

\begin{tabular}{lll}
\hline TSR & Rotor & MaxY+ \\
\hline 8 & Front & 18.485 \\
& Rear & 60.263 \\
12 & Front & 27.172 \\
& Rear & 64.009 \\
16 & Front & 38.191 \\
& Rear & 70.625 \\
\hline
\end{tabular}

\subsection{Computational simulation}

The numerical simulation has been carried out using available CFD solver, ANSYS Fluent 19.2. Setting up the CFD Simulation is detailed in Table 3. A steady-state simulation has been carried out first to facilitate convergence. This solution has been taken as the initial field for
Table 3 The information of solver setting

\begin{tabular}{ll}
\hline Item & Solver setting \\
\hline Type of solver & Pressure-based \\
Viscous model & $\mathrm{K}-\varepsilon$ realizable \\
Near-wall treatment & Standard wall function \\
Velocity-pressure coupling algorithm & SIMPLE \\
Pressure & Second order \\
Momentum & Second-order Upwind \\
Turbulent kinetic energy & Second-order Upwind \\
Turbulent dissipation rate & Second-order Upwind \\
Time step & $0.000,041,667 \mathrm{~s}$ \\
\hline
\end{tabular}

the subsequent unsteady calculations. In the unsteady simulations, a second-order implicit scheme is used for the discretization in time. Considering the frequency $(f)$ 


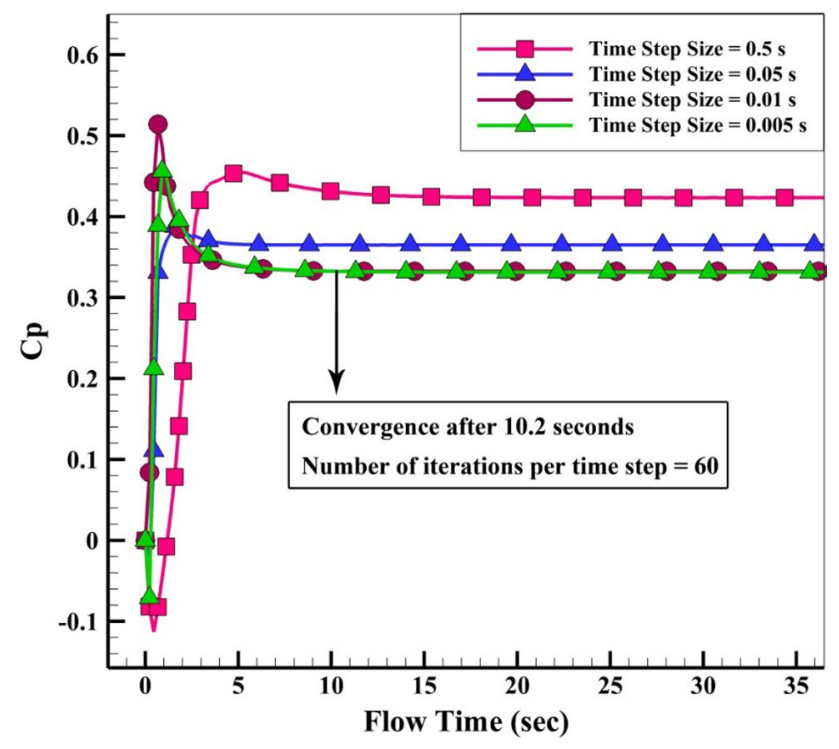

Fig. 3 Investigation of the unsteady simulation stability

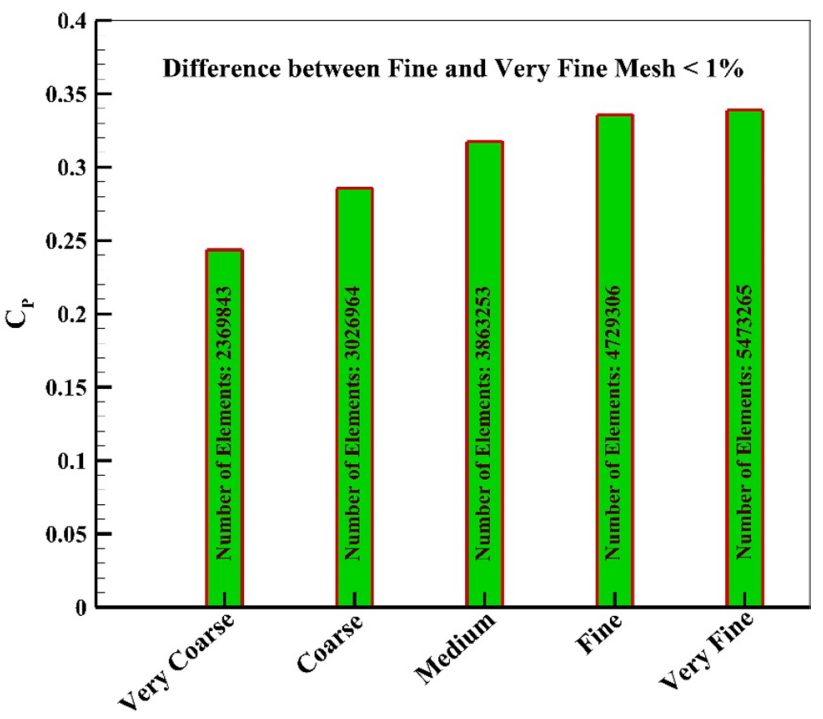

Fig. 4 Grid independence test for NREL Phase VI wind turbine rotor

of $1200 \mathrm{~Hz}$, the time step size $(\Delta \mathrm{t})$ was calculated from $\Delta t=1 / 2 f$, resulting in a time step size of $0.000,041,667 \mathrm{~s}$. In these simulations, with the chosen time-step size, the maximum local Courant number has remained below 1 .

In Fig. 3 The details of unsteady simulation for the dual rotor wind turbine in the highest tip speed ratio is presented. According to the results, no change was observed after $10.2 \mathrm{~s}$ in the values of $\mathrm{Cp}$ for the time steps lower than $0.01 \mathrm{~s}$, which approves the convergence. Furthermore, in each time step considering the number of iterations, all residuals have been converged and fallen below the Convergence criteria $10^{-7}$.

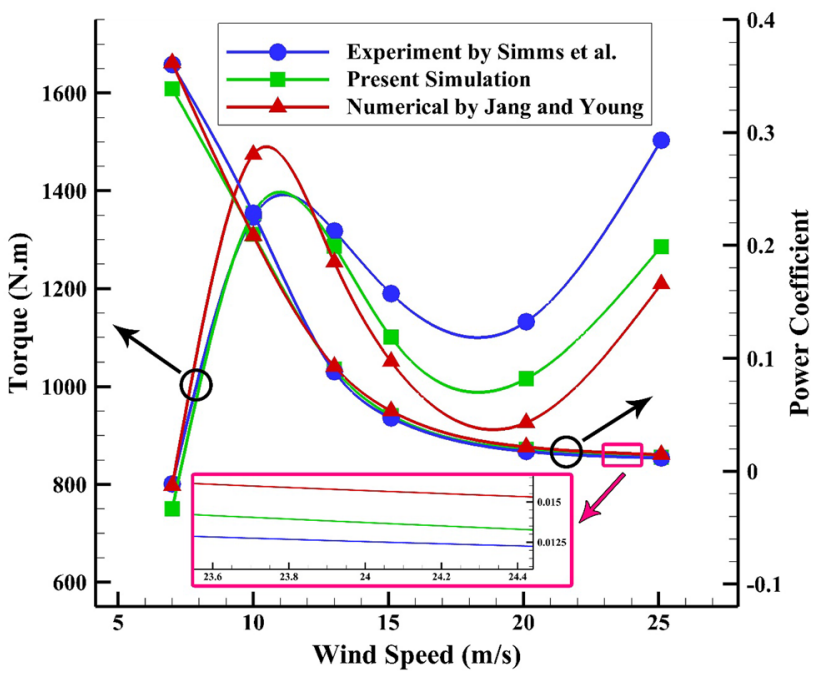

Fig. 5 Comparison between results from experimental and numerical considering torque and power coefficient

\section{Results of the study}

\subsection{Grid independence test}

To be sure that CFD results are independent of the mesh size, a grid-independent test has been carried out. Five different meshes, with 2,369,843, 3,026,964, 3,863,253, $4,729,306$, and 5,473,265 elements, were studied, and the performance of the wind turbine at the wind speed of $7 \mathrm{~m} / \mathrm{s}$ considering power coefficient for the cases was analyzed. As depicted in Fig. 4, the difference of power coefficient between fine and very fine grid systems is less than 1 percent. Based on this comparison, the mesh with 4,729,306 has been considered for the CFD analysis.

\subsection{Validation}

\subsubsection{Torque and power coefficient}

Low-speed shaft torque and power Coefficient and obtained from CFD analysis, which can be calculated according to Eqs. (18) and (19), were compared with the experimental data provided by NREL [5] as well as the data from previous numerical studies and illustrated in Fig. 5. According to the figure, the model predictions for different wind speeds are in good agreement with both experimental and the former study data [7]. The error observed at higher wind speeds can be explained by separation phenomena and lower accuracy of the turbulence model for separated flows. The near-wall flow is not resolved but modeled by using the socalled "wall functions". It is known that the wall-functions are not accurate in the vicinity of separation and reattachment points, and, consequently, cannot very accurately predict 


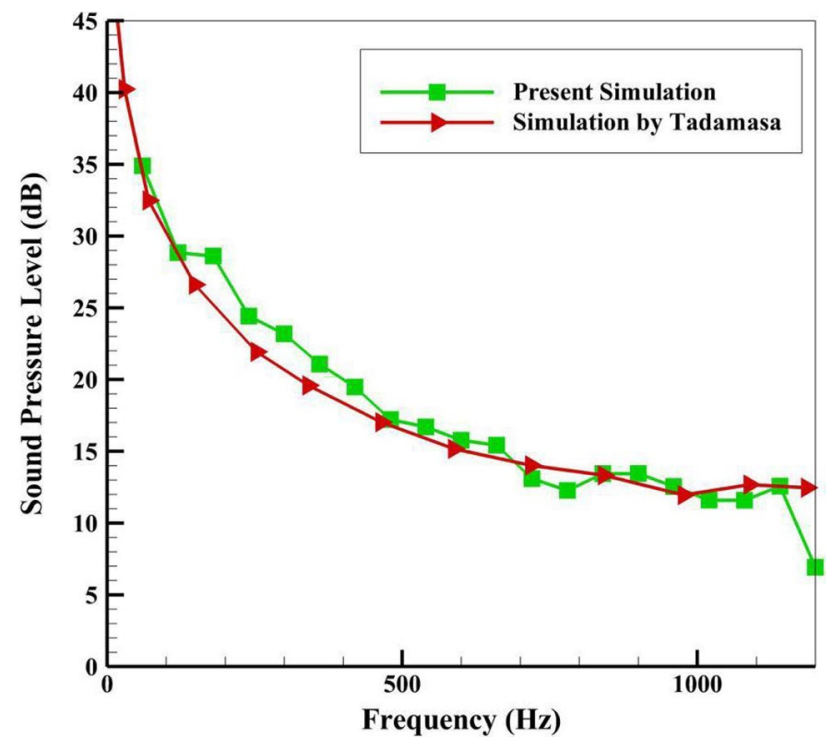

Fig. 6 Comparison between sound pressure level measured with simulation and Tadamasa and Zangeneh [16] at $7 \mathrm{~m} / \mathrm{s}$

the separation point. This principally reduces the prediction accuracy if separation is involved.

Low-speed shaft torque and power coefficient are given by:

$$
\begin{aligned}
& \mathrm{T}=\mathrm{nC}_{\mathrm{T}}\left(\frac{1}{2} \rho \mathrm{V}_{0}^{2} \mathrm{AL}\right) \\
& \mathrm{C}_{\mathrm{P}}=\frac{\mathrm{P}_{\text {out }}}{\mathrm{P}_{\text {in }}}=\frac{\mathrm{T} \cdot \omega}{\frac{1}{2} \rho \mathrm{V}_{0}^{3} \mathrm{~A}}
\end{aligned}
$$

Fig. 7 Comparison of $C_{p}$ under different tip speed ratios between CRWT and SRWT

\subsubsection{Acoustic validation}

Considering the sound pressure level at the receiver location, which is defined by the Eq. (20), validation of the applied model for aeroacoustic simulation was done.

$L_{p}=10 \log _{10}\left(\hat{p}^{2} / \hat{p}_{r e f}^{2}\right)$

Comparing the simulation results with the data from previous research, as depicted in Fig. 6 shows the appropriate accuracy of the current computational aeroacoustic analysis with the results obtained by Tadamasa and Zangeneh [16]. Comparison is based on sound pressure level at the location of the receiver defined in IEC 6140011 international standard, which is on-axis $17.029 \mathrm{~m}$ (rotor diameter $/ 2+$ tower height) from the rotor and at the bottom of the wind turbine's tower.

\subsection{Aerodynamic performance}

The performance of SRWT, as well as CRWT, have been scrutinized through the study of $C_{p}$ variation with changing TSR. For CRWT, the rotational speed of the rear rotor is considered constant and equal to $72 \mathrm{rpm}$, while the front rotor speed of rotation varies to have different amounts of TSR, as well as define the effect of the rotational speed of the front rotor on the performance of CRWT.

Tip speed ratio of CRWT can be defined as follows:

$T S R_{C R W T}=\frac{R_{\text {rear }} \omega_{\text {front }}}{V_{0}}+\frac{R_{\text {rear }} \omega_{\text {rear }}}{V_{0}}$

This study investigates a wide range of TSR to have a better evaluation of wind turbine operation. The overall performance of SRWT and CRWT over a range of TSR (2-18) is depicted in Fig. 6. Comparing power coefficients

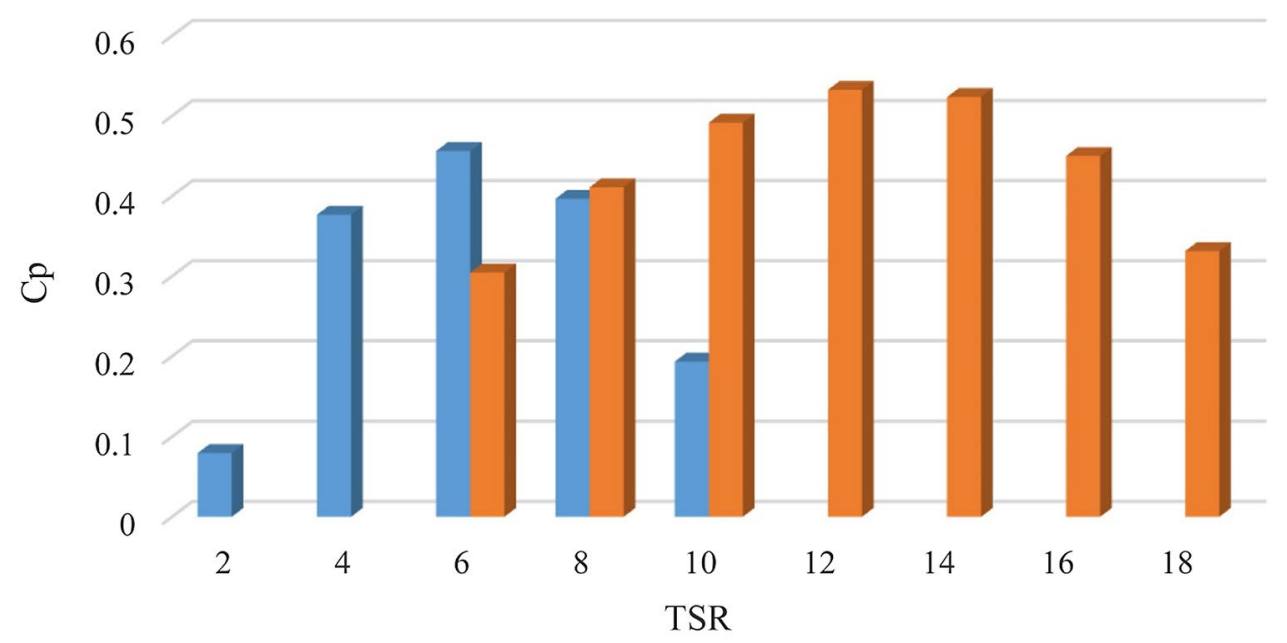

- Single Rotor $\quad$ Dual Rotor 


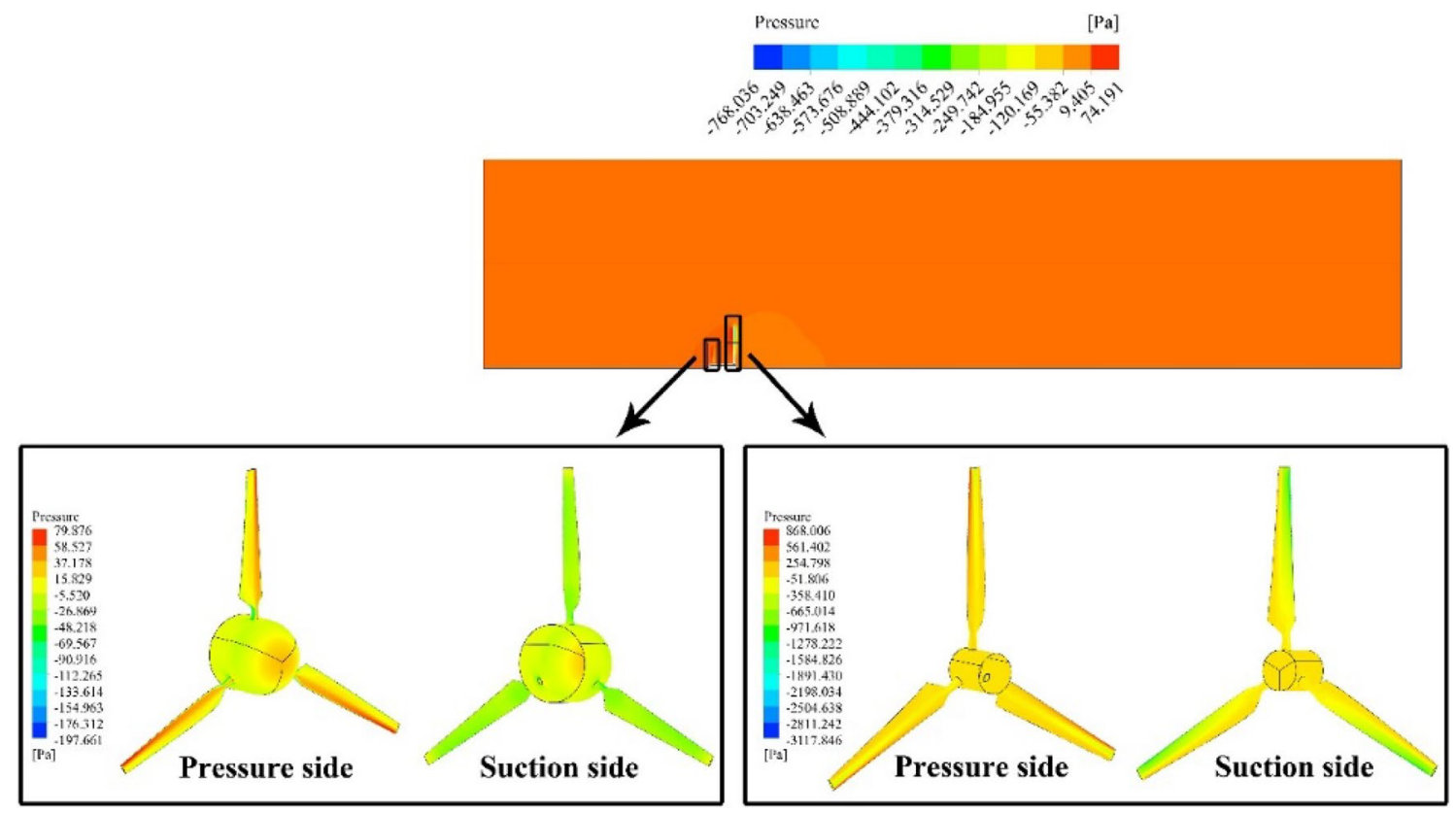

Fig. 8 View of pressure contours on the blades of CRWT at TSR $=8$

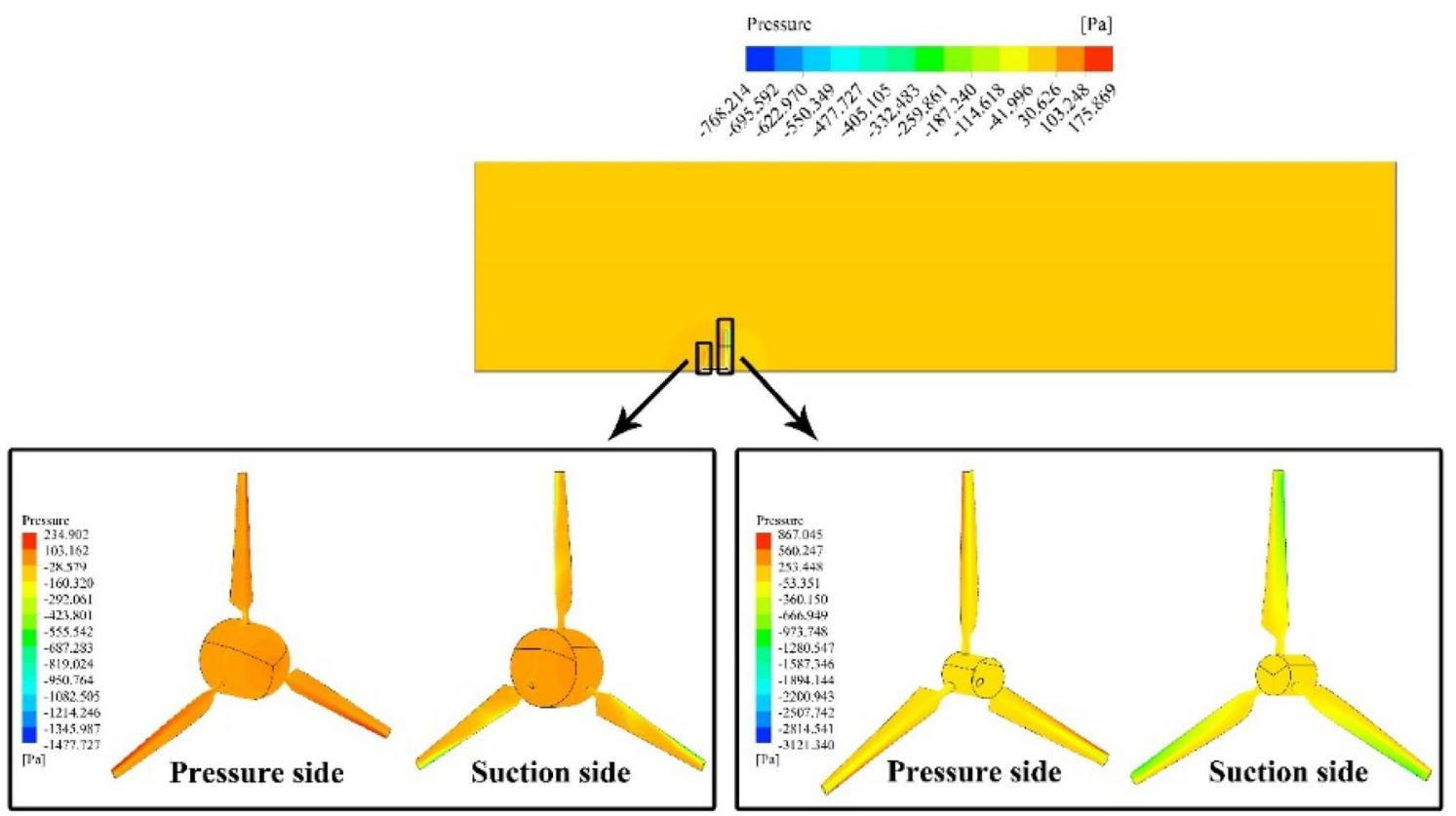

Fig. 9 View of pressure contours on the blades of CRWT at TSR $=12$

against TSR based on results from numerical simulation reveals that in the SRWT case, the performance enhances as tip speed ratio increases. The maximum $C_{p}$ in TSR $=6$ is 0.45 , but an inverse relation between $C_{P}$ and TSR is observed for TSR more than 6 . Increasing TSR results in reducing the power coefficient.
Results in Fig. 7 show that adding a rotor to conventional SRTW can enhance the total performance of the wind turbine. While the peak power coefficient for SWRT is 0.45 and obtained at TSR $=6$, the optimum $C_{P}$ for CRWT is 0.53 , which is achieved at TSR $=12$. After this tip speed ratio, $C_{p}$ decreases along with augmenting TSR. 


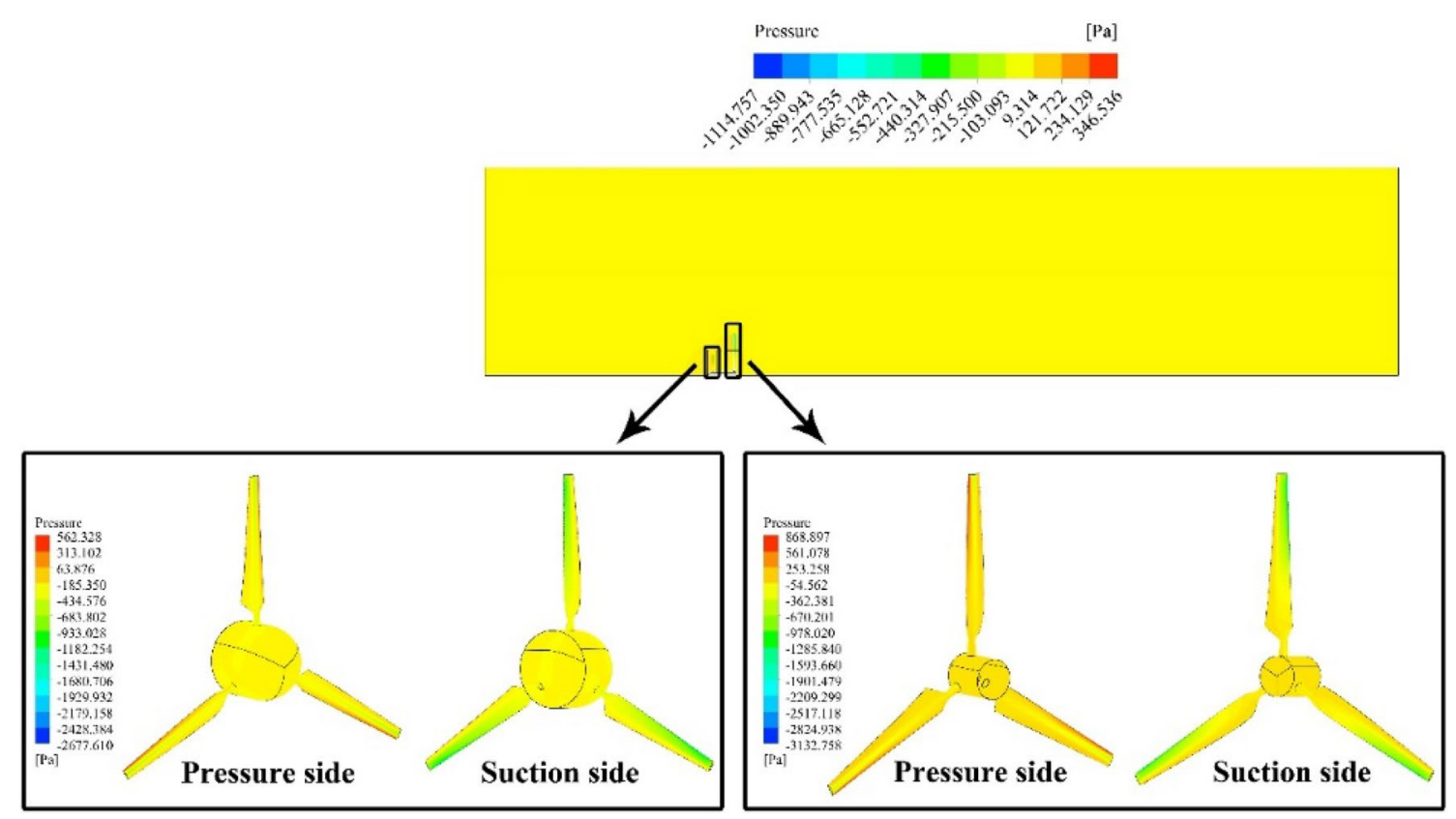

Fig. 10 View of pressure contours on the blades of CRWT at TSR $=16$

Fig. 11 Streamlines passing through the front and rear blades of CRWT at TSR $=8$

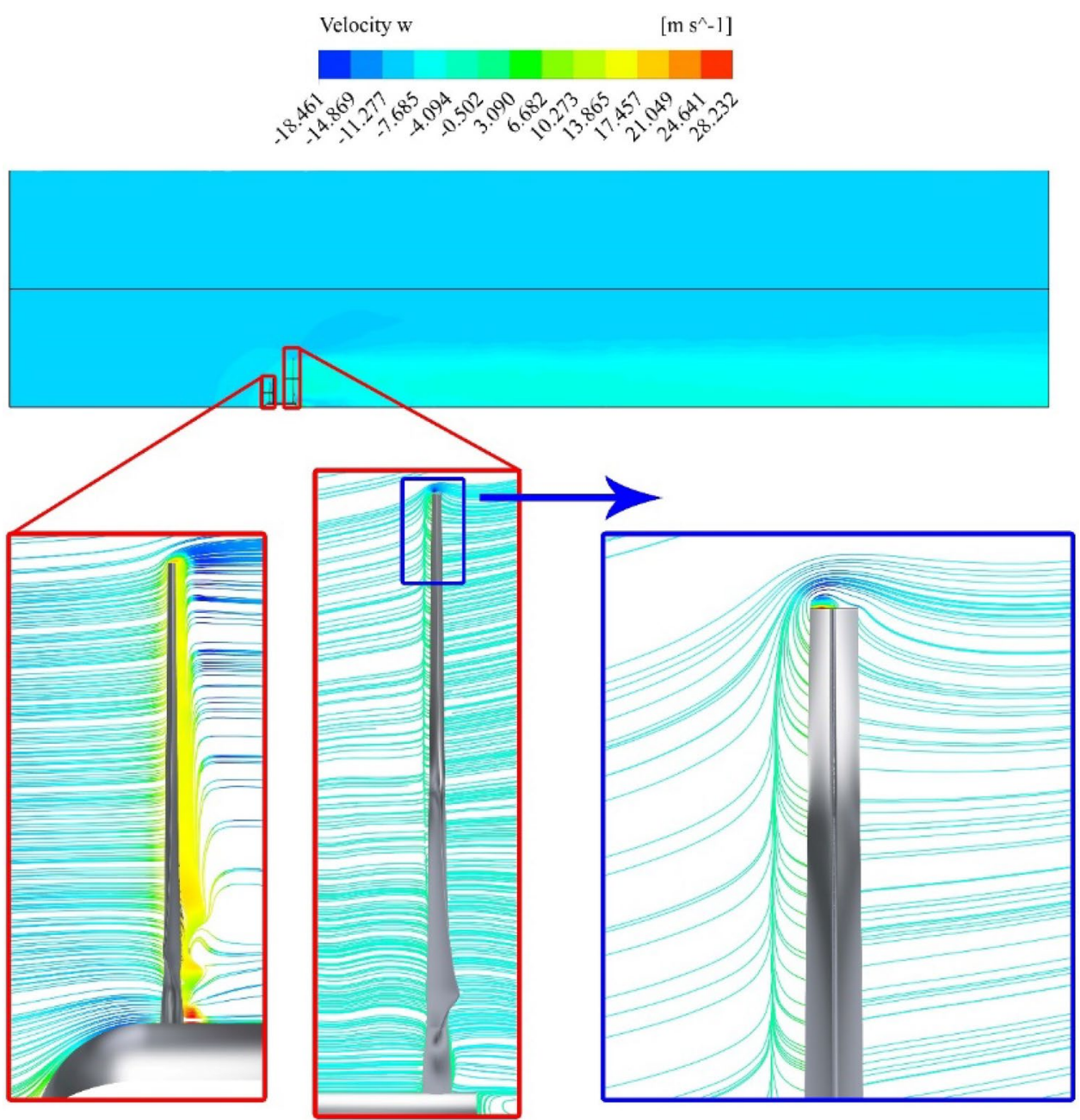

SN Applied Sciences

A SPRINGER NATURE journa 
Fig. 12 Streamlines passing through the front and rear blades of CRWT at TSR $=12$

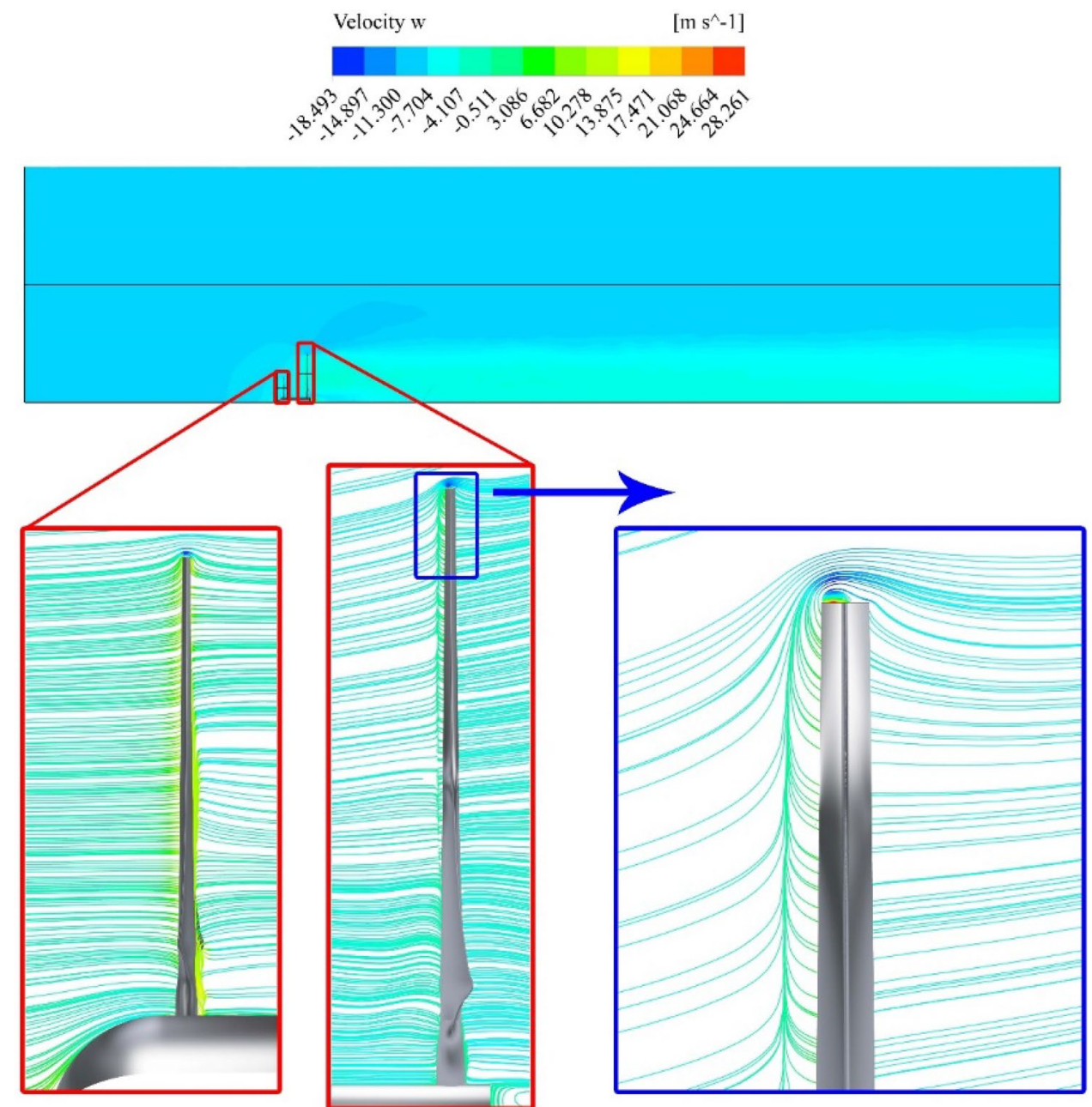

Figures 8,9 and 10 illustrate pressure contours on front and rear rotors of CRWT at three tip speed ratios.

Since the rotor RPM of the rear blade is fixed, no considerable increase in pressure contours observed with increasing tip speed ratio, while increasing TSR effectively influence pressure contours on the front blade. As TSR increase, the pressure level on surfaces of front rotors augments, due to the higher rotational velocity of the blade.

the velocity field around the front and rear rotors of CRWT is illustrated in Figs. 11, 12, and 13. As can be seen in the figures, there is a region near the hub behind the rotors with high velocity, which shows the poor aerodynamic performance of blades at the root area. It is because of design reasons since thick airfoils are used in these sections to support the blade structurally. It is the reason for adding a small rotor in front of the original blade the same as this current study to harness the wind energy in these sections.

As an influence of the front rotor, the pressure level in the near region of the rear rotor reaches its maximum value, and velocity in two directions reaches zero.
Following this, the streamlines move forward, and the stagnation line is formed at the surface of the rear blade.

\subsection{Aeroacoustic performance}

The acoustic analysis presented in this section has been performed under the constant wind speed of $7 \mathrm{~m} / \mathrm{s}$ for SRWT and CRWT. In the CRWT case, the rotational speed of the rear rotor kept constant, and the effect of changing rotor RPM of the front rotor on the noise generated by CRWT was investigated. The results have been obtained by applying the $\mathrm{FW}-\mathrm{H}$ acoustic analogy, which is an integral form solution to the Lighthill equation considering an observer located at the point specified by IEC 61400-11 international standard. Figure 14 shows the sound pressure levels for the frequency ranging from $60-1200 \mathrm{~Hz}$ at the receiver location for SRWT and CRWT with different TSRs.

As illustrated in the figure, the sound pressure levels of CRWT are higher in comparison with SRWT. Besides, with 
Fig. 13 Streamlines passing through the front and rear blades of CRWT at TSR $=16$

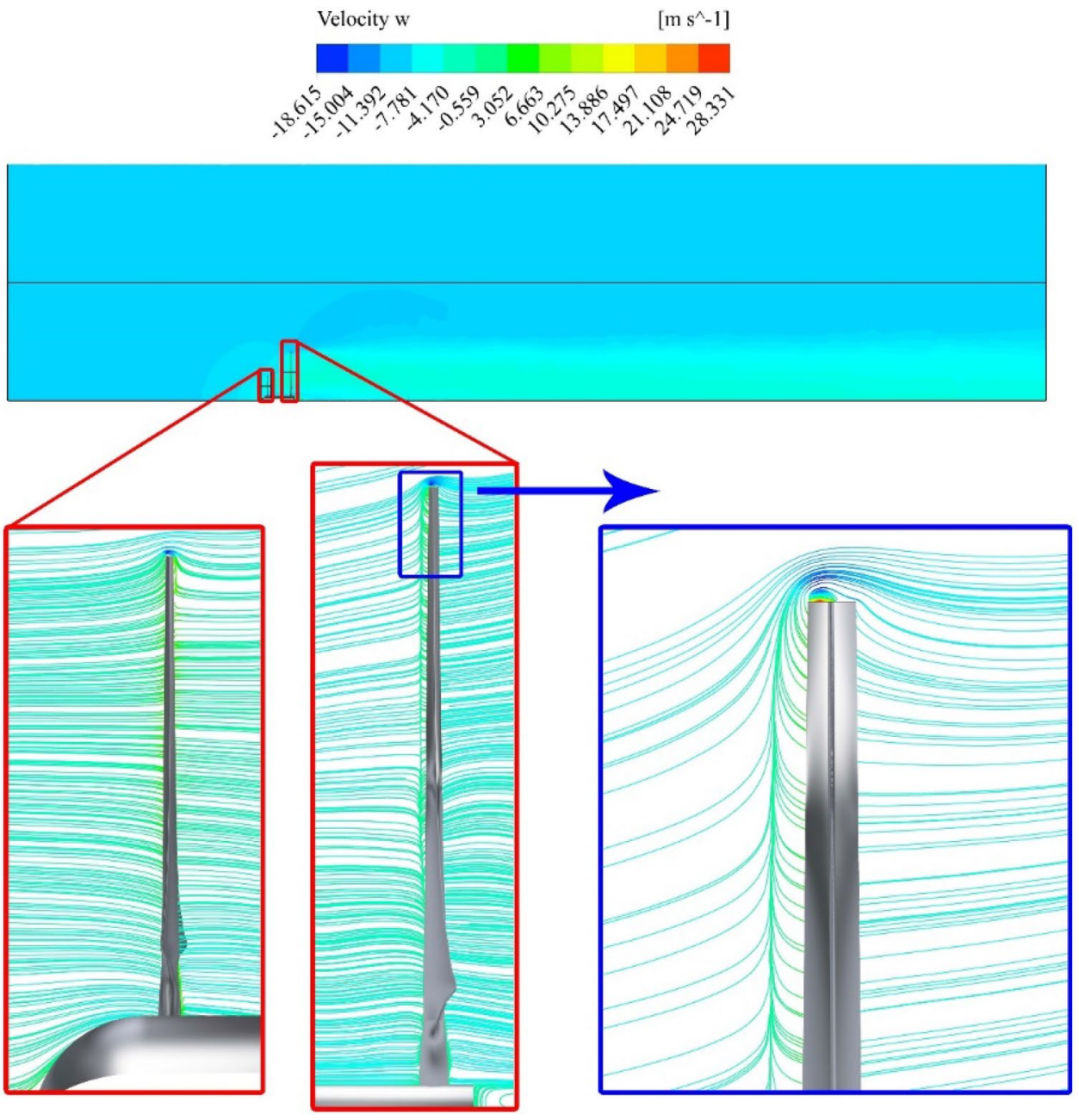

increasing TSR, the noise generated from CRWT becomes higher.

According to Figs. 15, 16 and 17, the highest pressure level is observable at the tip of the rear blade. It reveals that the tip of the blades can be regarded as the dominant noise source for all TSRs. On the other hand, increasing TSR leads to augment overall sound pressure levels.

\section{Discussion}

Previously, many researchers studied the aerodynamic performance of $C R$ wind turbines and found out that the power output enhanced considerably compared to conventional (single rotor) wind turbines, and observed that the power output enhanced considerably compared to conventional (single rotor) wind turbines [9-15], but the aeroacoustics performance of these wind turbines have been not investigated, while aeroacoustic behavior of any wind turbine is a significant aspect which must be considered, mainly when the wind turbine is considered
Fig. 14 Total noise from SRWT and CRWT blade at various tip speed ratios 
Fig. 15 Contours of sound pressure level on rear and front blades of CRWT at TSR $=8$
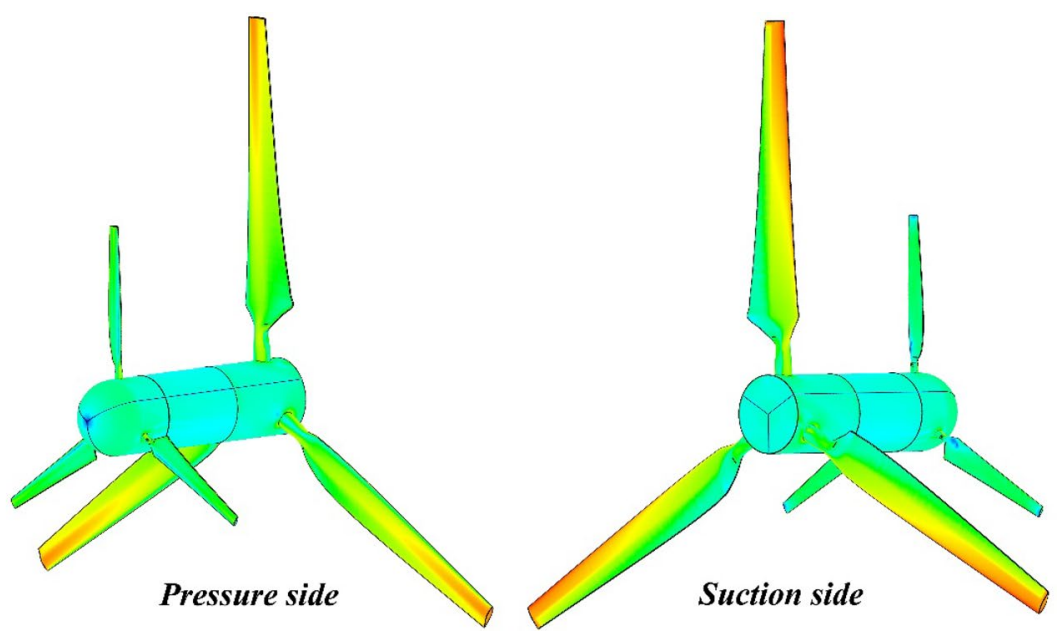

Fig. 16 Contours of sound pressure level on rear and front blades of CRWT at TSR $=12$
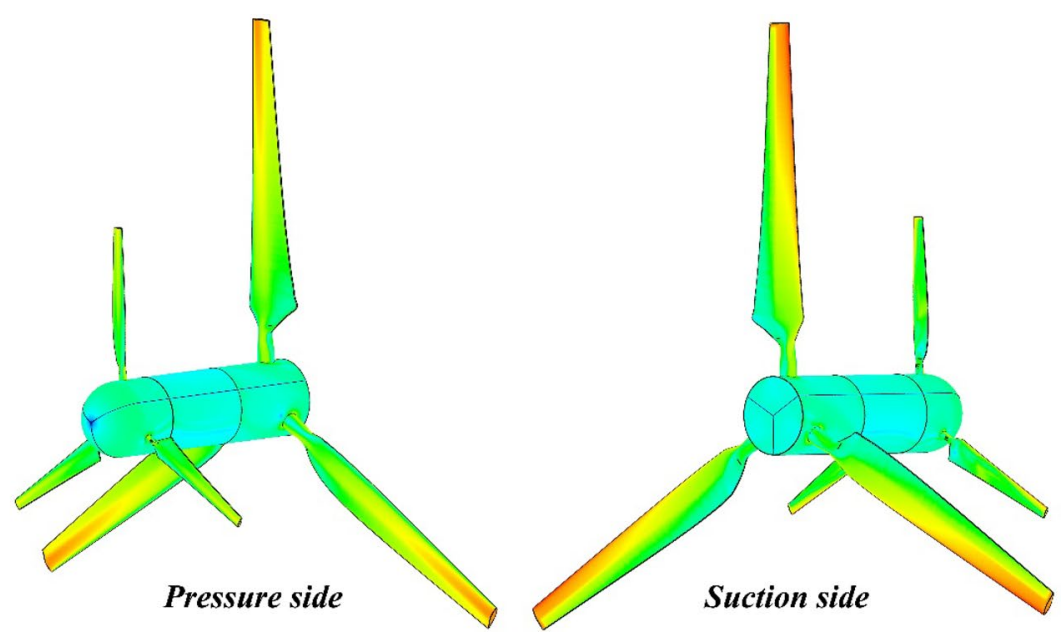

Fig. 17 Contours of sound pressure level on rear and front blades of CRWT at TSR $=16$
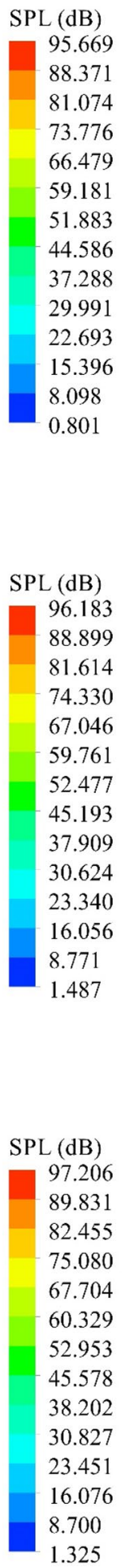

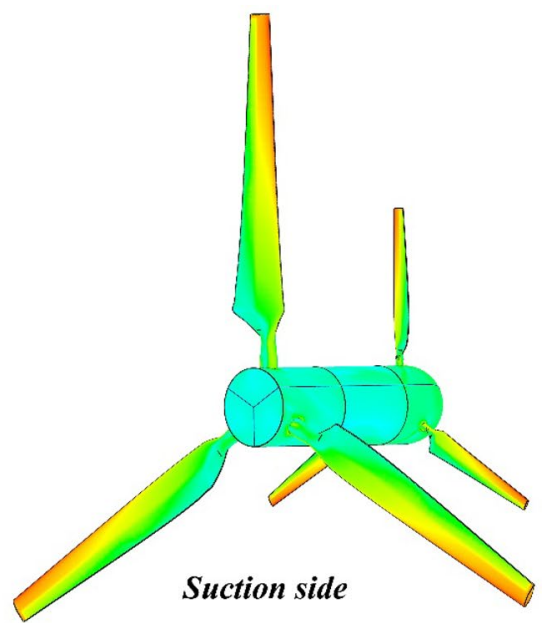

to be installed in the places near areas people live and work, since the noise emission from wind turbine can have negative influences on their environmental quality of life. Considering the fact that precise prediction of aeroacoustic noise is the first step for the later studies on noise mitigation measures, besides since there is no attention to the aeroacoustic behavior of CR wind turbines, the focus of this research is both aerodynamic and aeroacoustic performance of counter-rotating wind turbines. 
The result of power performance in the present research has been compared with the former studies carried out on a single rotor wind turbines [5-7] and counter-rotating wind turbines [9-14]. The same trend has been observed for power enhancement in CR wind turbines. The results of aeroacoustic performance have been only compared and validated for the single rotor wind turbine [16-19], for the reason that the aeroacoustics of $C R$ wind turbines have not been comprehensively studied earlier. The comparison of aeroacoustic results also showed high correctness of the current numerical work. The results of our study revealed that despite the efficiency of CR wind turbines is significantly greater than single-rotor wind turbines, the noise generated from these turbines is higher, too.

\section{Conclusions}

This work was carried out to study the effect of varying rotational velocity on the produced power as well as noise generated from CRWT. For this purpose, the three-bladed geometry of NREL Phase VI wind turbine has been selected as SRWT, and CRWT configuration was achieved by adding a 50\% scaled of SRWT as a front rotor, which was placed upwind and upstream of the rear rotor. A variety of tip speed ratios has been considered for CRWT by changing the rotor RPM of the front blade, while the rotational speed of the rear rotor was constant and equal to $72 \mathrm{rpm}$. The power coefficient and sound pressure levels of CRWT under different TSR have been predicted utilizing URANS and $\mathrm{FW}-\mathrm{H}$ acoustic analogy. The near-field flow has been calculated, and then, the data of pressure fluctuations on the blades of front and rear rotors have been used to calculate the generated noise of CRWT. The numerical simulation outputs have been validated using the data from former studies and experimental data for NREL Phase VI. All data have been achieved considering constant free wind velocity of $7 \mathrm{~m} / \mathrm{s}$. The results show that adding an auxiliary rotor to SRWT can improve efficiency, also increasing the rotational speed of the front rotor leads to higher power coefficient for TSR ranging from 6 to 12, but for tip speed ratios higher than 12 , with increasing TSR, power coefficient declines. Investigating the aeroacoustic performance of CRWT revealed that generated noise increases along with augmenting TSR. According to the outputs, at the same wind speed of $7 \mathrm{~m} / \mathrm{s}$, CRWT with a TSR of 12 can achieve a power coefficient that is higher than that of SRWT, but the sound pressure level is also higher than a single rotor wind turbine. The results of this article define that although CRWT has a better performance in comparison to SRWT, the noise generated by CRWT is also higher, which must be considered and controlled, especially in the residential areas.

\section{Compliance with ethical standards}

Conflict of interest The authors declare that they have no conflict of interest.

\section{References}

1. Muiruri PI, Motsamai OS, Ndeda R (2019) A comparative study of RANS-based turbulence models for an upscale wind turbine blade. SN Appl Sci 1(3):237

2. Asumadu $\mathrm{R}$ et al (2019) 3-Dimensional numerical study of wave-induced seabed response around three different types of wind turbine pile foundations. SN Appl Sci 1(11):1401

3. Putri NP et al (2019) Experimental studies on the effect of obstacle upstream of a savonius wind turbine. SN Appl Sci 1(10): 1216

4. Newman BG (1983) Actuator-disc theory for vertical-axis wind turbines. J Wind Eng Ind Aerodyn 15(1-3):347-355

5. Hand MM et al (2001) Unsteady aerodynamics experiment phase VI: wind tunnel test configurations and available data campaigns. No. NREL/TP-500-29955. National Renewable Energy Lab., Golden, CO., US

6. Park YM, Chang BH, Cho TH (2007) Numerical simulation of wind turbine scale effects by using CFD. In: 45th AIAA aerospace sciences meeting and exhibit

7. Mo J-O, Lee Y-H (2012) CFD investigation on the aerodynamic characteristics of a small-sized wind turbine of NREL PHASE VI operating with a stall-regulated method. J Mech Sci Technol 26(1):81-92

8. Appa K (2002) Energy Innovations Small Grant (EISG) Program (Counter-rotating wind turbine system) Technical Report, California, US

9. Jung SN, No T-S, Ryu K-W (2005) Aerodynamic performance prediction of a $30 \mathrm{~kW}$ counter-rotating wind turbine system. Renew Energy 30(5):631-644

10. Lee S, Kim H, Lee S (2010) Analysis of aerodynamic characteristics on a counter-rotating wind turbine. Curr Appl Phys 10(2):S339-S342

11. Habash RW et al (2011) Performance of a contrarotating small wind energy converter. In: ISRN Mechanical Engineering 2011

12. Ozbay A, Tian W, Hui H (2016) Experimental investigation on the wake characteristics and aeromechanics of dual-rotor wind turbines. J Eng Gas Turbines Power 138(4):042602

13. Wang $Z$ et al (2018) An experimental study on the aerodynamic performances and wake characteristics of an innovative dual-rotor wind turbine. Energy 147:94-109

14. Koehuan VA, Kamal S (2017) Investigation of counter-rotating wind turbine performance using computational fluid dynamics simulation. Mater Sci Eng Conf Ser 267(1):012034

15. Hwang B, Lee S, Lee $S$ (2013) Optimization of a counter-rotating wind turbine using the blade element and momentum theory. J Renew Sustain Energy 5(5):052013

16. Tadamasa A, Zangeneh M (2011) Numerical prediction of wind turbine noise. Renew Energy 36(7):1902-1912

17. Mo J-O, Lee Y-H (2011) Numerical simulation for prediction of aerodynamic noise characteristics on a HAWT of NREL phase VI. J Mech Sci Technol 25(5):1341 
18. Maizi M et al (2018) Noise reduction of a horizontal wind turbine using different blade shapes. Renew Energy 117:242-256

19. Giridhar R, Farokhi S, Taghavi R (2019) Aerodynamic noise generated by the NREL Phase VI wind turbine rotor. In: AIAA Scitech 2019 Forum

20. Zhu WJ et al (2018) Wind turbine noise generation and propagation modeling at DTU wind energy: a review. Renew Sustain Energy Rev 88:133-150

21. Ghasemian M, Nejat A (2015) Aerodynamic noise prediction of a horizontal axis wind turbine using improved delayed detached eddy simulation and acoustic analogy. Energy Convers Manag 99:210-220

22. Shih T-H, Liou WW, Shabbir A, Yang Z, Zhu J (1995) A new k- $\varepsilon$ eddy-viscosity model for high reynolds number turbulent flows - model development and validation. Comput Fluids 24(3):227-238

23. Lighthill MJ (1952) On sound generated aerodynamically general theory. Proc R Soc Lond SerA 211:564-587
24. Curle N (1955) The influence of solid boundaries upon aerodynamic sound. Proc R Soc A 231:505-514. https://doi. org/10.1098/rspa.1955.0191

25. Ffowcs Williams JE, Hawkings DL (1969) Sound generation by turbulence and surfaces in arbitrary motion. Philos Trans-act A Math Phys Eng Sci 264:321-342

26. Ffowcs Williams JE, Dowling AP, Goldstein ME (1978) Sound production in a moving stream. Philos Trans R Soc Lond Ser A Math Phys Sci 288(1353):321-349

27. ANSYS Fluent Theory Guide, ANSYS, Inc., 275 Technology Drive Canonsburg, PA 15317, November 2011

28. Farassat $F$ (2007) Derivation of formulations 1 and $1 A$ of Farassat. technical report NASA TM 214853

Publisher's Note Springer Nature remains neutral with regard to jurisdictional claims in published maps and institutional affiliations. 